\title{
Russian scientists see red over clampdown
}

A young Russian biologist who was taking samples to a collaborative institute in France has been accused of attempting to smuggle bioweapons by Russia's federal security service, the FSB. He has been interrogated repeatedly by FSB agents and prevented from leaving the country. His job also now looks uncertain. But experts say that the accusations are absurd.

Oleg Mediannikov's Kafkaesque nightmare began on 12 December 2006 at Moscow's Sheremetyevo airport, as he was about to board a plane to Marseilles. Customs officials confiscated 20 phials containing non-pathogenic strains of a typhus vaccine approved by the Russian health ministry for export to France, along with Mediannikov's computer and USB memory sticks. Mediannikov initially thought there was a minor problem with the paperwork. But more than eight months on, the interrogations continue.

Mediannikov, who works at the Gamelaya Institute of Epidemiology and Microbiology in Moscow, studies Rickettsia prowazekii, the bacterium spread by lice that causes epidemic typhus. The institute's laboratory of rickettsial ecology, headed by Irina Tarasevich, has a long-established collaboration with the Rickettsial Unit of the University of the Mediterranean in Marseilles, led by Didier Raoult. The two institutes are World Health Organization Collaborating Centres for Rickettsial Reference and Research.

Raoult planned to compare the protein spectrum of two strains of $R$. prowazekii - Madrid E and EVir - produced more than 20 years ago in chicken embryos in Russia and since held at the Gamelaya Institute, with similar strains produced more recently in France from

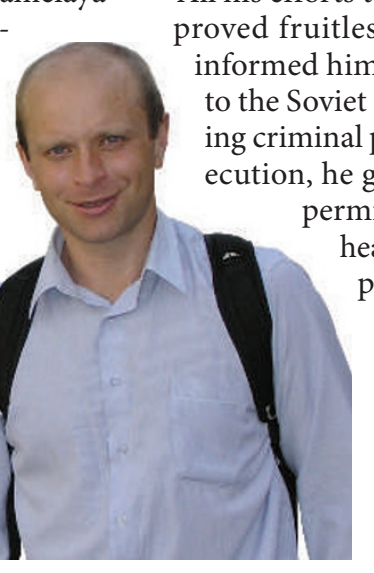

"If things get worse, we will demand that the FSB interrogates the deputy health minister, who approved the export of the material." - Oleg Mediannikov trip to Marseilles without the samples. On his return to Moscow in January, he was told that the confiscated material had been sent to a secret laboratory - code-named the 47 th military research institute - for an 'expert assessment'. Three weeks later he was told that an additional assessment - the first allegedly concluded the materials were benign - was necessary before the materials could be returned. This second assessment is still pending.

But the situation is causing other problems for Mediannikov. On 13 February, he intended to go on a tourist trip to Cameroon, only to learn at Moscow's Domodedovo airport that there was an official order preventing him from leaving the country. When he demanded an explanation, a customs official said the order "must not be discussed". His passport was confiscated and returned two months later by regular post.

All his efforts to clarify the situation have proved fruitless. In early June, customs him that the FSB - successor n criminal proceedings. To avert prosgave them the valid export ermission signed by the deputy health minister. In addition, he presented letters from Tarasevich and Raoult attesting to the harmlessness of the strains and their sole use for scientific purposes.

Nonetheless, criminal proceedings were initiated on 26 June - and the accusations are severe. The indictment, of which Nature has obtained a copy, cites Article 188/2 of the Criminal Code of the Russian Federation on smuggling materials that might be used for preparing weapons of mass destruction. People guilty of illicit trafficking of mammalian cell cultures. Both strains are not considered to be virulent and are used in vaccinations against typhus. The work is part of a larger research project on the pathogenesis of $R$. prowazekii, led by Raoult and funded by France's basic-research agency, the CNRS.

Mediannikov was allowed to continue his weapons-delivery systems can be sentenced to up to seven years in prison.

Raoult says that he is stunned. "Something like this has never happened in 20 years of our centres' collaboration," he says. "Oleg spent two years working in my lab. He is a very good, dynamic and responsible scientist." His

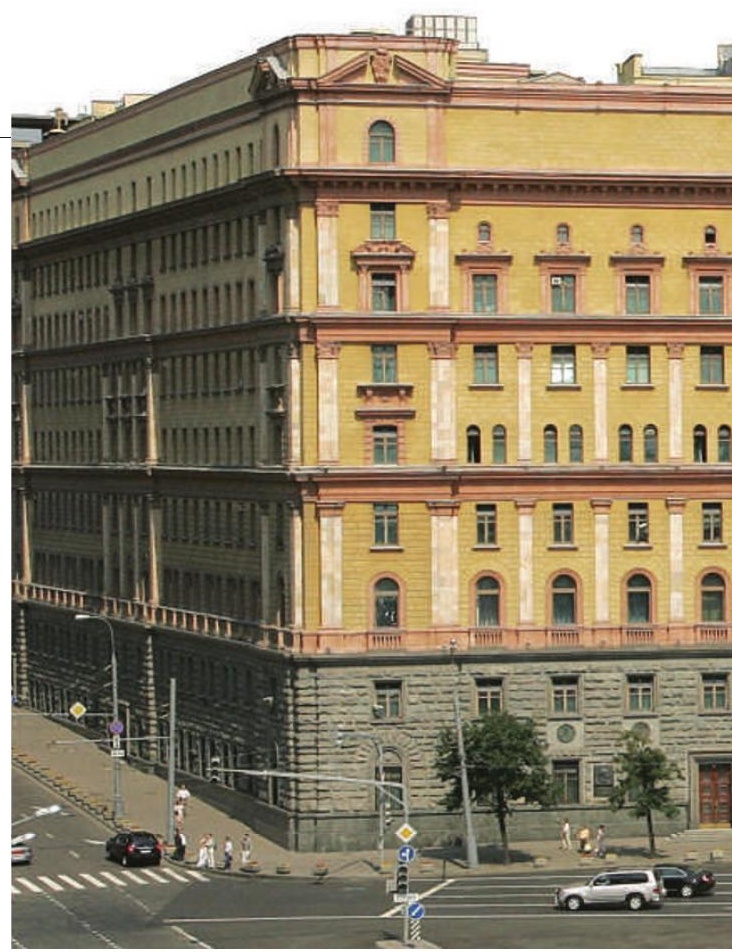

work has been instrumental in helping fight typhus in Russia, he adds. Typhus bacteria are not considered potential bioterrorism agents by other governments. "It is a terrible disease, but the agent is so difficult to grow that it doesn't make any sense to use it for bioweapons," says Raoult.

This week, Mediannikov told Nature that the deputy director of his institute had been approached by the FSB and that Mediannikov has now been told to resign or face the sack.

\section{On the up}

Mediannikov's case illustrates a worrying resurgence in Russian scientists being accused of wrong-doing. In 2000, for example, thermophysicist Valentin Danilov of Krasnoyarsk State Technical University was arrested for allegedly passing classified information to China. He was acquitted in 2003, but taken into custody again after the Russian Supreme Court overturned the acquittal in 2004. And in 2004, Igor Sutyagin, a social scientist formerly with the US and Canada Institute in Moscow, was sentenced to 15 years in a labour camp for allegedly passing classified data on nuclear submarines and missile-warning systems to a British company.

The FSB also suspected chemist Oleg Korobeinichev, head of the laboratory of chemical kinetics and combustion in Novosibirsk, of having divulged state secrets to the United States. But the charges were dropped in June 2006, and Korobeinichev received a public apology from local legal authorities. On 27 August, the FSB finally withdrew the charges against physicists Oleg and Igor Minin, who had been accused of revealing state secrets.

"There have been worse times in this coun- 


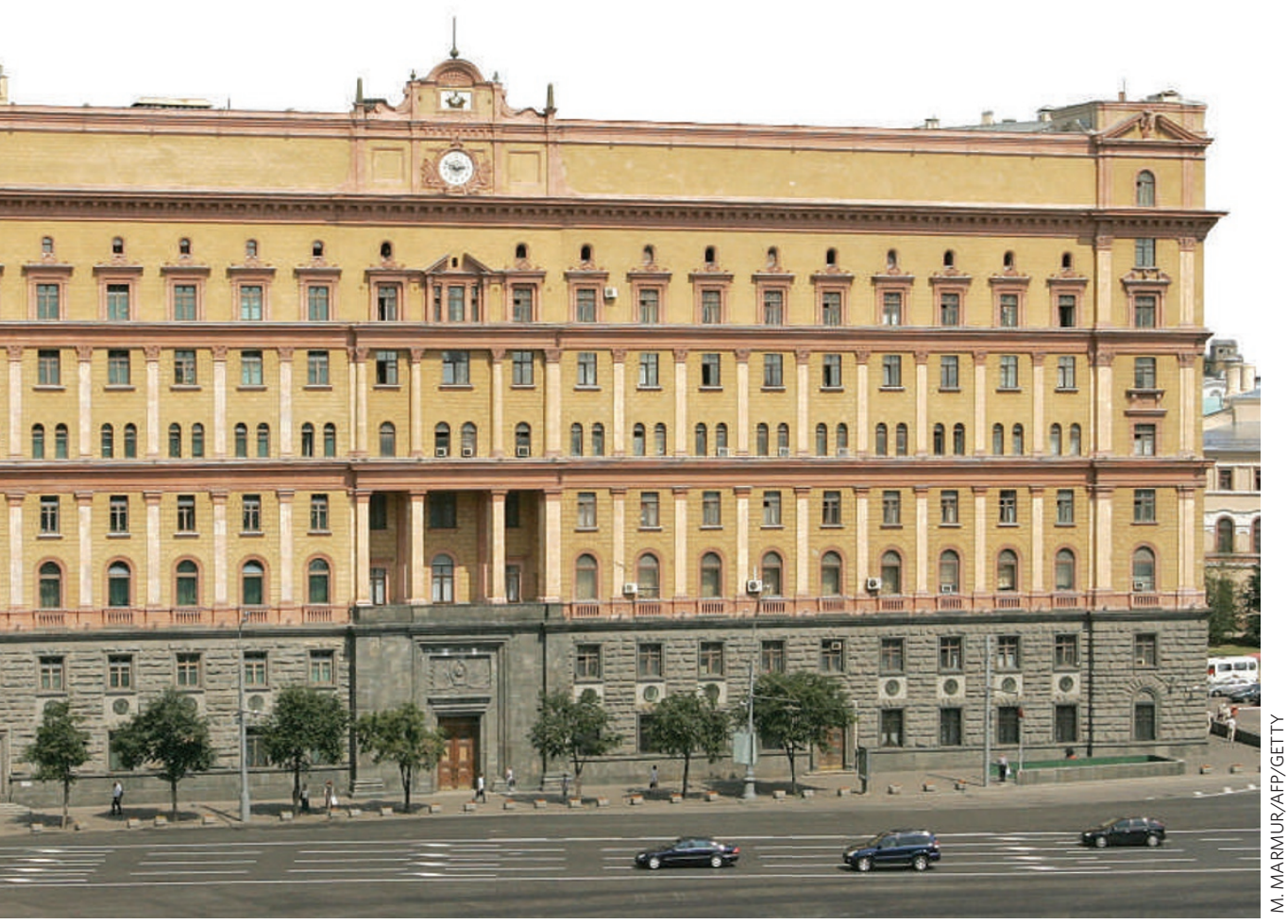

Russia's FSB (above) has detained several scientists for 'smuggling' scientific samples such as Rickettsia prowazekii (right) out of the country.

try," says a Russian expert on non-proliferation on condition of anonymity. "But Vladimir Putin has untied the hands of the FSB, and we do see a trend here towards strengthening state control over all spheres of life, including science."

In May, the FSB warned in a secret report to President Putin that biological samples taken from Russians could be used abroad to produce 'genetic weapons'. Consequently, the export of human specimens was temporarily banned. The order was reversed two weeks later after an outcry in the media and the scientific community.

"Publicity does help in such cases," says Konstantin Severinov, a biochemist who has a joint affiliation at the Institute of Molecular Genetics in Moscow and at Rutgers University in New Jersey. Severinov was himself 'interviewed' by an FSB official in June. "I told the guy straight away that the whole genetic-weapon craze is nothing but lunacy and paranoia," he says.

Over the past couple of months, Mediannikov has been summoned six times to the FSB interrogation department in Moscow. Interviews - about his biography, scientific advisers, collaborators, research, and so on - lasted for up to four hours, but took place in a "quite pleasant" atmosphere, he says. Mediannikov is now waiting for the result of the second expert assessment. "If there's anything in it that might back the charge we will insist on a third, independent assessment," he says. "If things get worse, we will also demand that the FSB interrogates the deputy health minister, who approved the export of the material." He points out that scientists from the Gamelaya Institute have previously taken similar samples to France without any problems.

One customs officer, Mediannikov says, hinted to him that customs were "ordered" by the FSB to take action against him. And Severinov says that Mediannikov might have been shopped to the FSB by an over-zealous member of his institute's 'first department'. These notorious 'security' departments are obligatory at Russian research institutes - a relic of Soviet times - and they maintain close connections with the FSB.

Mediannikov's situation is serious, as is always the case when FSB investigators are involved, say legal experts. But if convicted only of 'ordinary' smuggling, he may yet get away with a modest penalty fee, they say. A date for the trial has not been set. He is not in custody, but experts doubt that he would be allowed to leave Russia as long as the investigation continues.

Quirin Schiermeier 